УДК 634.8.044; 631.95

DOI 10.30679/2219-5335-2021-1-67-102-112

СПОСОБ УСКОРЕНИЯ

ПРОЦЕССА ВЫВЕДЕНИЯ

НОВЫХ СОРТОВ ВИНОГРАДА

ПРИ ИСПОЛЬЗОВАНИИ

ГИББЕРЕЛЛОВОЙ КИСЛОТЫ И СУБСТРАТОВ

Малых Григорий Павлович

д-р с.-х. наук, профессор

главный научный сотрудник

лаборатории питомниководства

винограда

e-mail: malih.grig@yandex.ru

Авдеенко Ирина Алексеевна

младший научный сотрудник

лаборатории питомниководства

винограда

e-mail: irinaawdeenko@yandex.ru

Всероссийский научно-исследовательский институт виноградарства и виноделия имени Я.И. Потапенко - филиал

Федерального государственного

бюджетного научного учреждения

«Федеральный Ростовский

аграрный научныий центтр»,

Новочеркасск, Россия

Сегет Ольга Леонидовна

канд. с.-х. наук

научный сотрудник

лаборатории управления

воспроизводством в ампелоценозах

и экосистемах

e-mail: olya.yakovtseva@mail.ru

Федеральное государственное

бюджетное научное учреждение

«Северо-Кавказский федеральный

научный центр садоводства,

виноградарства, виноделия»,

Краснодар, Россия

Виноградарство перспективно в зонах

Северо-Кавказского региона,

однако сортимент зон не всегда

отвечает современным требованиям:
UDC 634.8.044; 631.95

DOI 10.30679/2219-5335-2021-1-67-102-112

\section{METHOD FOR ACCELERATING THE PROCESS \\ OF BREEDING \\ THE NEW GRAPE VARIETIES \\ USING GIBBERELLIC ACID AND SUBSTRATES}

Malykh Grigoriy Pavlovich

Dr. Sci. Agr., Professor

Senior Research Associate

of Nursery Grape

Laboratory

e-mail: malih.grig@yandex.ru

Avdeyenko Irina Alekseyevna

Junior Research Associate

of Nursery Grape

Laboratory

e-mail: irinaawdeenko@yandex.ru

All-Russian Scientific

Research Institute

of Viticulture and Winemaking

named after Ya.I. Potapenko-

branch of the Federal State Budgetary

Scientific Institution «Federal Rostov

Agricultural Research Center»,

Novocherkassk, Russia

Seget Olga Leonidovna

Cand. Agr. Sci.

Research Associate

of Reproduction Control

in the Ampelocenoses

and Ecosystems Laboratory

e-mail: olya.yakovtseva@mail.ru

Federal State

Budget Scientific Institution

"North Caucasian Federal

Scientific Center of Horticulture,

Viticulture, Wine-making»,

Krasnodar, Russia

Viticulture is promising in the areas

of the North Caucasus Region,

however, the assortment of zones

does not always meet to modern 
экологичности, низкой энергоемкости производства в сочетании с высоким качеством урожая. В настоящее время сорт в виноградарстве стал одним из основных средств в решении проблемы повышения и стабилизации продуктивности насаждений. В связи с этим селекция винограда на устойчивость к биотическим и абиотическим условиям среды, наряду с высокой продуктивностью и качеством, особенно актуальны.

Повышение всхожести семян - направление в селекции, требующее особого внимания. Селекционный процесс занимает продолжительное время, что в условиях интенсификации сельскохозяйственного производства неприемлемо.

Из-за особенностей онтогенеза винограда и низкой всхожести семян передача сеянцев на конкурсное сортоиспытание возможна не раньше, чем через 8-10 лет после посева семян. В нашей работе определен простой и эффективный способ увеличения выхода сеянцев путем достратификационного замачивания. В опыте использовались различные концентрации гибберелловой кислоты. Минимальная концентрация гибберелловой кислоты 0,01 \% обеспечила почти $100 \%$ выход сеянцев. Увеличение концентрации кислоты до 0,04 \% стимулировало выход сеянцев по сравнению с контрольным вариантом, однако чрезмерное увеличение концентрации оказывает ингибирующий эффект. Разработан и апробирован состав субстрата для посева гибридных семян винограда в вазоны, обеспечивающий высокие показатели роста и развития растений на 1 и 2 годах жизни. В целом замачивание семян и правильный подбор состава субстрата, описанные в данной работе, позволяют сократить селекционный процесс на 3-4 года и раньше передать сеянцы винограда на государственное сортоиспытание.

Ключевые слова: ВИНОГРАД, СЕЛЕКЦИЯ, ГИБРИДНЫЕ СЕМЕНА, ВЫХОД СЕЯНЦЕВ, ЗАМАЧИВАНИЕ СЕМЯН, СУБСТРАТ, СТРАТИФИКАЦИЯ requirements: environmental friendliness, low energy intensity of production combined with high quality of crop. Currently, the variety in viticulture has become one of the main means in solving the problem of increasing and stabilizing the productivity of plantations. In this regard, the selection of grapes for resistance to biotic and abiotic environmental conditions, along with high productivity and quality are especially relevant. Increasing in seed germination is a direction in breeding that requires special attention. The breeding process takes a long time, which is unacceptable in conditions of intensification of agricultural production. Due to the peculiarities of grape ontogenesis and low seed germination, the transfer of seedlings for competitive variety testing is possible no earlier than 8-10 years after sowing seeds. In our work, a simple and effective way to increase in the yield of seedlings by pre-stratification soaking is defined. In the experiment, the various concentrations of gibberellic acid were used. The minimum concentration of gibberellic acid of $0,01 \%$ ensured an almost $100 \%$ yield of seedlings. An increase in acid concentration up to $0,04 \%$ stimulated the seedlings yield in comparison with the control variant, however, an excessive increase in concentration has an inhibitory effect. The composition of the substrate for sowing hybrid grape seeds in flowerpots was developed and tested, which provides high growth and development of plants in the 1 and 2 years of life. In general, the soaking of seeds and the correct selection of the substrate composition described in this work can reduce the breeding process by 3-4 years and allow us to transfer the seedlings earlier to the State variety testing.

Key words: GRAPES, BREEDING, HYBRID SEEDLING, SEED EXIT, SEED SOAKING, SUBSTRATE, STRATIFICATION 
Плодоводство и виноградарство Юга России № 66(6), 2020 г.

Введение. Выведение новых сортов винограда - длительный и кропотливый процесс. В среднем на выведение нового сорта необходимо запастись терпением на два десятилетия. В первую очередь, гибридные семена высевают в гряды и при наилучших условиях проводят их выкопку в первый год. Зачастую по причине слабого роста, недостаточного вызревания сеянцы приходится оставлять на 2 года, с последующей выкопкой и закладкой на период зимнего хранения. Весной сеянцы высаживают в гибридный питомник на постоянное место $[1,2]$.

Период плодоношения сеянцев наступает на 5-6 год после посева или на 3-4 год после посадки в гибридный питомник, в котором проводится изучение плодоношения сеянцев не менее 3 лет. Далее, для выделения элитных сеянцев и их дальнейшего конкурсного испытания, каждый сеянец размножают (до 60 кустов), на что необходимо минимум 2 года. С третьего года посадки начинается этап изучения агробиологических характеристик и плодоношения сеянцев [3].

После проведения конкурсной проверки сеянец передают на государственное сортоиспытание по аналогичной схеме (не менее 6 лет) [4]. Главной причиной ретардации селекции является продолжительность индивидуального развития (онтогенеза) сеянцев и саженцев [5-11].

Общеизвестно, что гибридные семена винограда имеют крайне низкую всхожесть. Для ускорения и увеличения прорастания семян в первый год жизни применяют различные способы замачивания семян до стратификации в растворах карбоната натрия $\left(\mathrm{Na}_{2} \mathrm{CO}_{3}=1-3 \%\right)$, сульфате аммония $\left(\left(\mathrm{NH}_{4}\right)_{2} \mathrm{SO}_{4}=\right.$ 0,25-3 \%), меди $(\mathrm{Cu})$, гидрокарбонате и хлориде натрия $\left(\mathrm{NaHCO}_{3} ; \mathrm{NaCl}\right)$, молочной, уксусной, никотиновой, индолилмасляной и масляной кислот в различных концентрациях. Однако несмотря на положительные результаты опытов по достратификационной обработке семян перечисленные растворы не получили широкого применения в селекции [12-17]. В последние годы наибольшее распространение в селекционной практике получили регуляторы роста 
на основе фитогормонов: ауксины, гиббереллины, цитокинины (природные регуляторы роста). Для успешного ускорения процесса селекции помимо использования ростостимулирующих препаратов необходимо правильно подобрать комбинацию субстрата и удобрений, обеспечивающих хорошее развитие корневой системы сеянцев винограда [18-21].

Задача исследований - ускорение процесса селекции новых сортов винограда из гибридных семян: повышение их всхожести, ускорение ювенильного этапа жизни растений путем предварительной обработки семян и применением специального субстрата, а также организацией оптимальных условий краткого годичного цикла.

Объекты и методы исследований. Все фенологические наблюдения осуществлялись по общепринятым в производстве методикам. Агротехника выращивания в гибридных питомниках сеянцев винограда стандартная: полив, подкормки, «зеленые» операции.

Опыты проводились следующей схеме:

I. Замачивание гибридных семян до стратификации, по 100 щт.:

1. контроль - общепринятая технология стратификации, замачивание семян до стратификации в $3 \%-$ м растворе $\mathrm{Na}_{2} \mathrm{CO}_{3}$;

2. замачивание семян до стратификации в $0,01 \%$ растворе гибберелловой кислоты;

3. замачивание семян до стратификации в $0,03 \%$ растворе гибберелловой кислоты;

4. замачивание семян до стратификации в $0,04 \%$ растворе гибберелловой кислоты.

II. Посев замоченных семян в субстраты, по 100 шт.:

1. чернозем (прототип);

2. глауконитовый песок;

3. конский навоз + глауконитовый песок + Грин Го 8-16-4 +10 СаО + чернозем $(1: 1: 1: 1)$. 
В середине декабря семена винограда вымачивали в воде при температуре $20-25^{\circ} \mathrm{C}$, после чего их повторно вымачивали в растворах гибберелловой кислоты, согласно схеме опыта I, в течение 24 часов. После всех замачиваний семена высевали в вазоны с субстратом на глубину 5-6 см и поливали. Далее вазоны помещают в стратификационную камеру с поддержанием температуры $25-27^{\circ} \mathrm{C}$ и влажности 85-90 \% до достижения прироста 60 см.

Обсуждение результатов. В опыте I использовались различные концентрации гибберелловой кислоты при замачивании семян до стратификации. Из данных рисунка 1 видно, что 1 вариант (общепринятая технология) уступает вариантам с замачиванием гибридных семян винограда в гибберелловой кислоте на 9,5-31,2 \% или в 1,12-1,52 раза, что является существенным в сложном селекционном процессе.

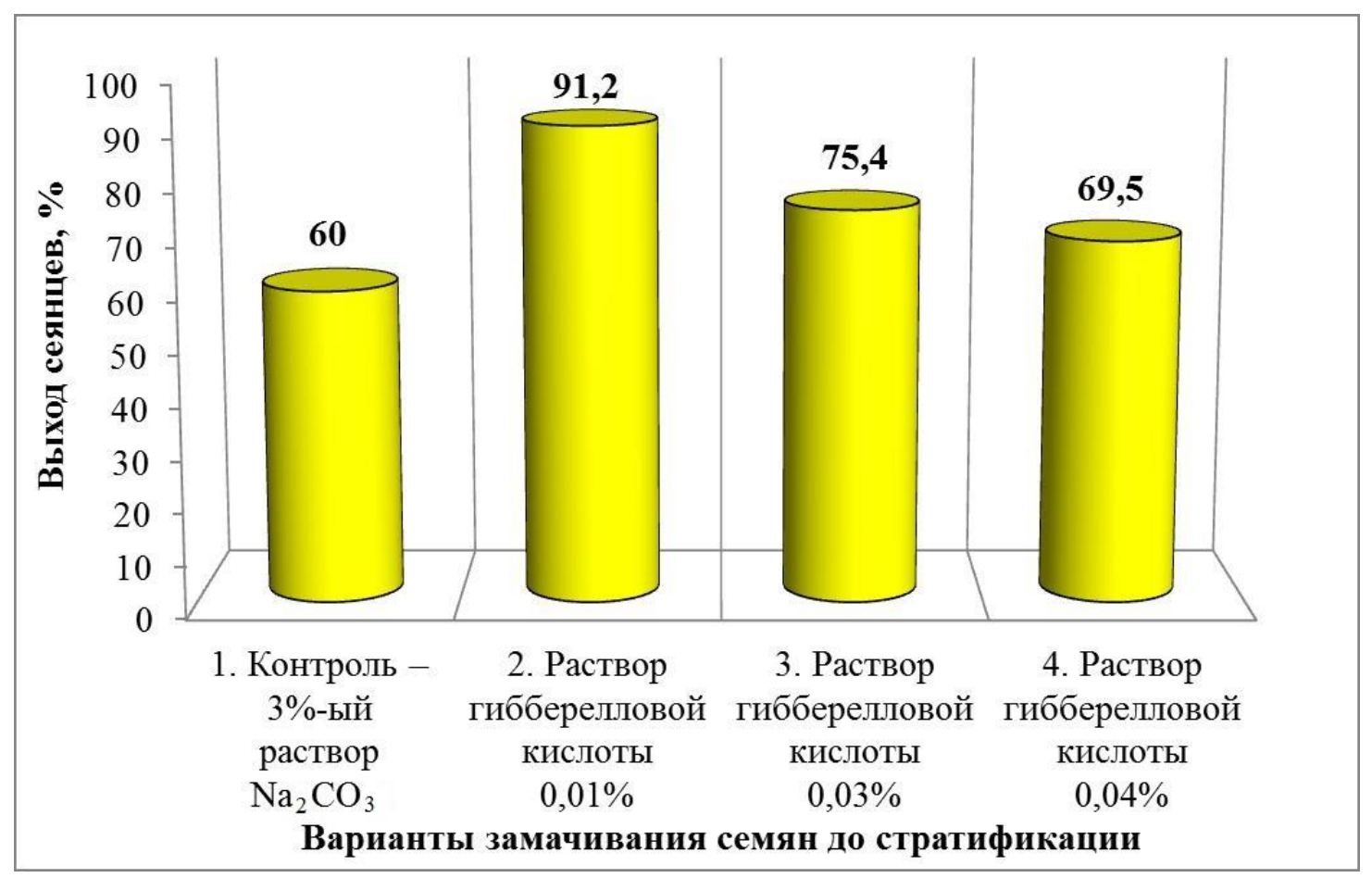

Рис. 1. Влияние гибберелловой кислоты на выход сеянцев

Наблюдается корреляция концентрации гибберелловой кислоты и выхода сеянцев, и можно сделать вывод, что минимальная концентрация 
наших опытов 0,01 \% (2 вариант) обеспечивает почти 100 \% высокий выход сеянцев, а именно 91,2 \%. Увеличение концентрации кислоты перед замачиванием до 0,04 \% стимулирует выход сеянцев по сравнению с контрольным вариантом, однако чрезмерное увеличение концентрации вызывает ингибирующий эффект.

В процессе наблюдений за фенологическим развитием сеянцев винограда в мае были определены площадь листовой поверхности и средний прирост побегов (рис. 2).

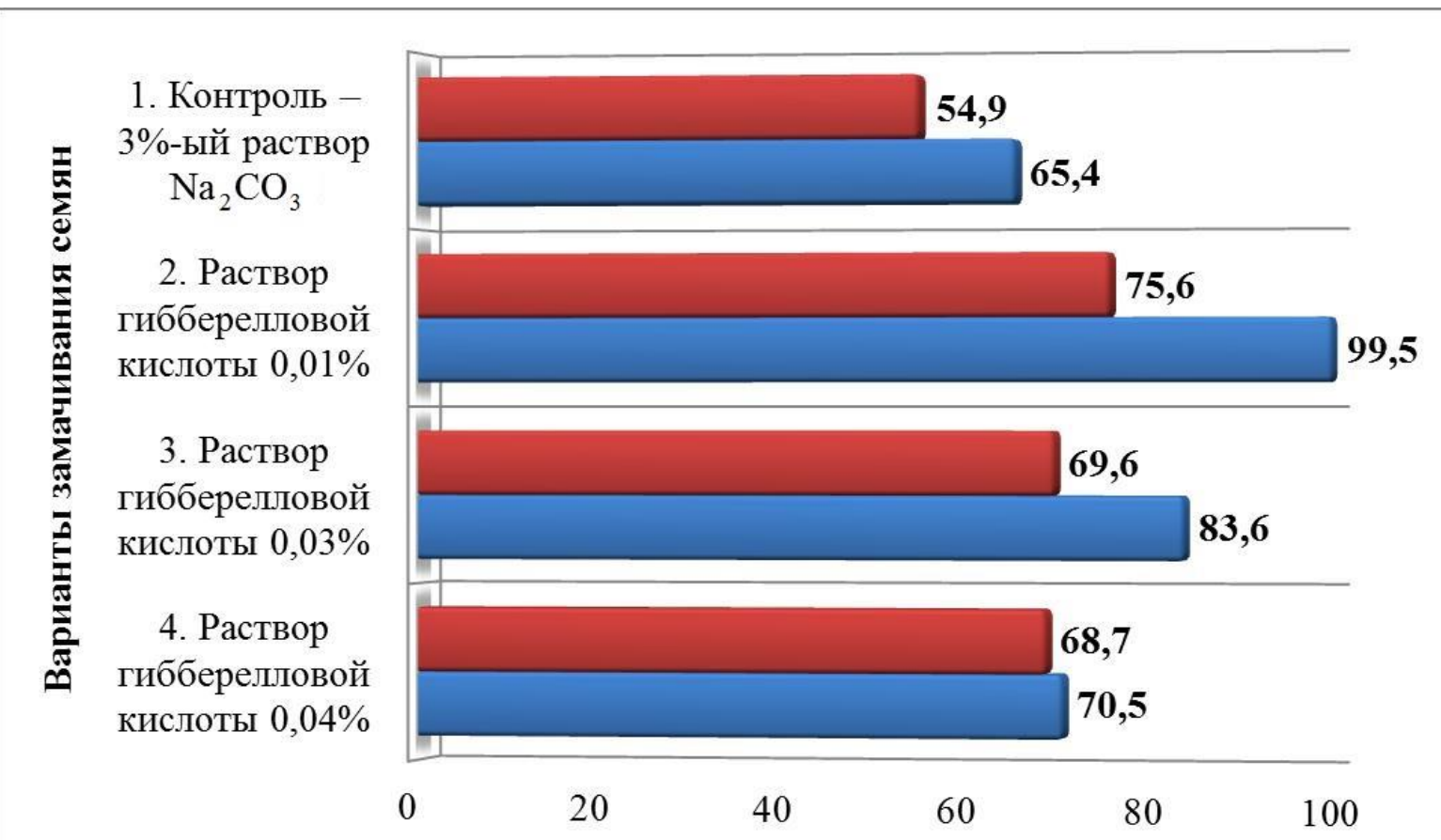

Площадь листовой поверхности, см$^{2}$; $\square$ Средний прирост побега в мае, см.

Рис. 2. Влияние предпосевного замачивания семян на фенологические показатели развития гибридных сеянцев в первый год жизни

Средний прирост побега в контрольном варианте составил всего 65,4 см, в то время как применение минимальной концентрации гибберелловой кислоты обеспечило средний прирост побега 99,5 см и площадь листовой поверхности 75,6 см², что в 1,52 и 1,38 раза больше, соответственно. 
Плодоводство и виноградарство Юга России № 66(6), 2020 г.

Различия в 3 и 4 вариантах опыта по площади листовой поверхности не были существенны (68,7-69,6 см²), однако была разница по длине прироста (на 13,1 см).

В опыте II изучалось совместное влияние субстрата (преимущественно) и замачивания в гибберелловой кислоте на выход сеянцев и показатели развития в первые 2 календарных года жизни сеянцев. Посев семян в различные субстраты производили в 2-х литровые усеченные вазоны на глубину 5-6 см (согласно схеме опыта II), которые после посева поливали и устанавливали в теплице.

В опытах использовалась разработанная нами установка, способная автоматически поддерживать необходимые оптимальные режимы температуры и влажности. После установки вазонов на стеллажи температуру под стеллажами устанавливают $20-25^{\circ} \mathrm{C}$, где создаются оптимальные условия для развития корневой системы. Когда прирост достигает 1,5 метра и начинается вызревание побегов у основания, температуру под стеллажами снижают до $12-15^{\circ} \mathrm{C}$. Спустя неделю поддержания низких температур растения готовятся вступить в состояние покоя, которое прерывают повышением температуры для ускорения плодоношения, после чего температуру снова снижают. Через 15 дней процедуру повышения и понижения температур повторяют. Осенью растения вступают в естественный период покоя, который прерывают включением нашего устройства, устанавливая температуру 25-26 ${ }^{\circ} \mathrm{C}$ и влажность воздуха 85-90\%.

Из рисунка 3 видно, что 1 и 2 варианты опыта не сильно различались исследуемым показателям, существенные различия наблюдались только по количеству заплодоносивших сеянцев, которые при посеве на глауконитовый песок составили 77 \%, что превышает вариант 1 на 10 \%. Использование специального состава субстрата (конский навоз + глауконитовый песок + Грин Го 8-16-4 + $10 \mathrm{CaO}+$ чернозем $(1: 1: 1: 1))$ обеспечивало хорошие ана- 
лизируемые показатели: выход сеянцев (88,7 \%); приживаемость на постоянном месте (98,7 \%); степень вызревания побега (84,6 \%); количество заплодоносивших побегов $(85,6)$.

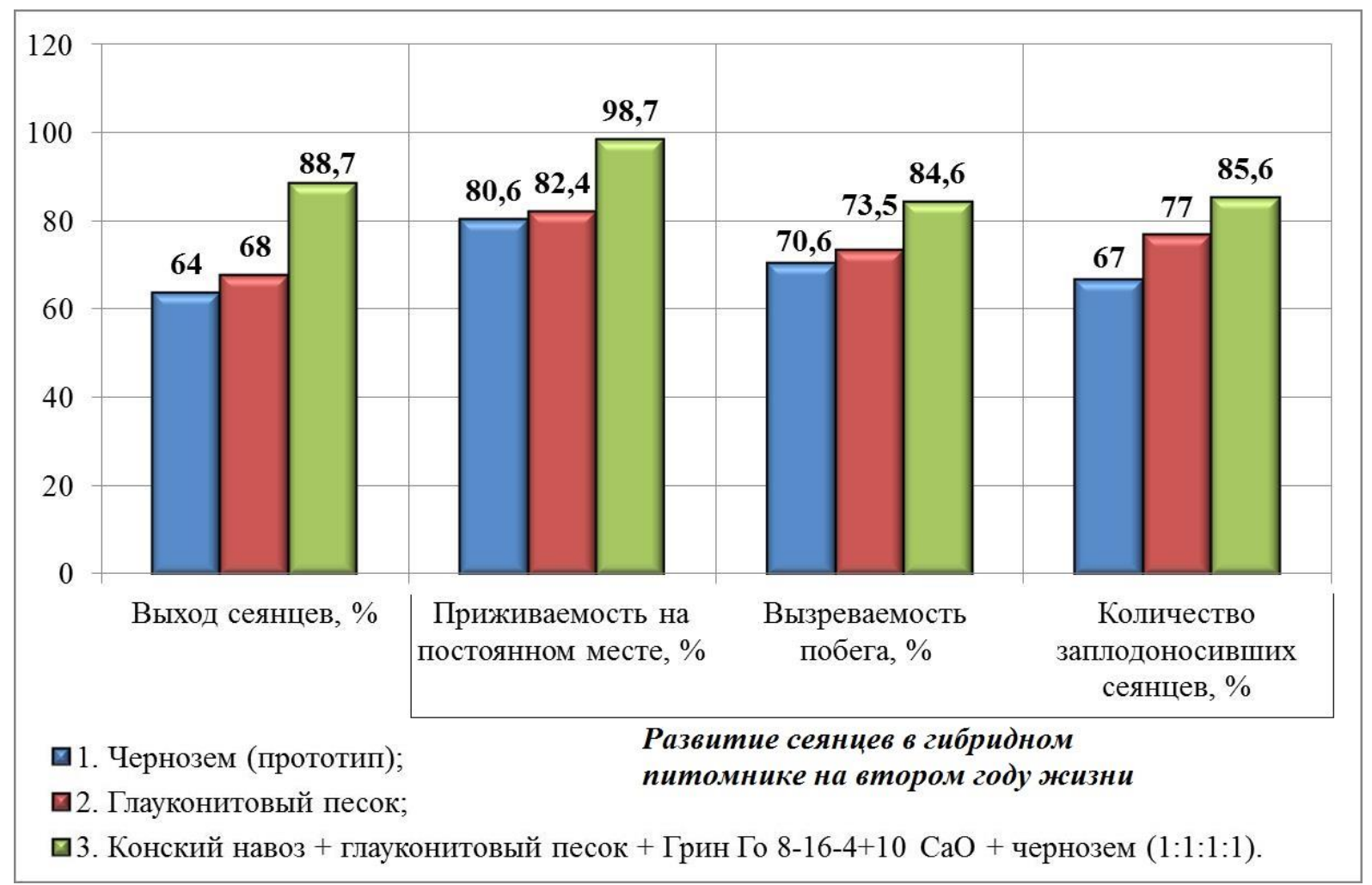

Рис. 3. Влияние состава субстрата на выход сеянцев винограда и их развитие в гибридном питомнике на втором году жизни

При выборе субстрата для посева семян винограда необходимо делать сложную смесь из различных элементов. Обеспечение оптимального уровня питания и структуры субстрата в первые годы жизни оказывает существенное влияние на выход сеянцев и важные показатели прироста в первые 2 года жизни сеянцев (рис. 4).

Средний прирост побега на моносубстратах (1 и 2 варианты) варьировал от 64 до 68 см (1 год жизни) и от 80,6 до 82,4 см (2 год жизни), и разница между приростами составила всего 4 и 1,8 см соответственно. 
Сеянцы такой длины позже вступят в плодоношение, что растянет длительность процесса селекции. При выращивании на специальном субстрате (3 вариант) длина побега в первый год жизни растений составила 88,7 см, а следовательно, превышала длину побега двух летних растений в 1 и 2 вариантах.

1. Чернозем (прототип);

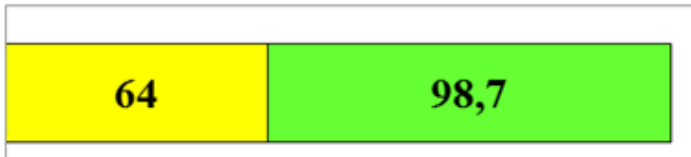

2. Глауконитовый песок;

3. Конский навоз + глауконитовый песок + Грин Го 8-16-4+10 CaO + чернозем $(1: 1: 1: 1)$.

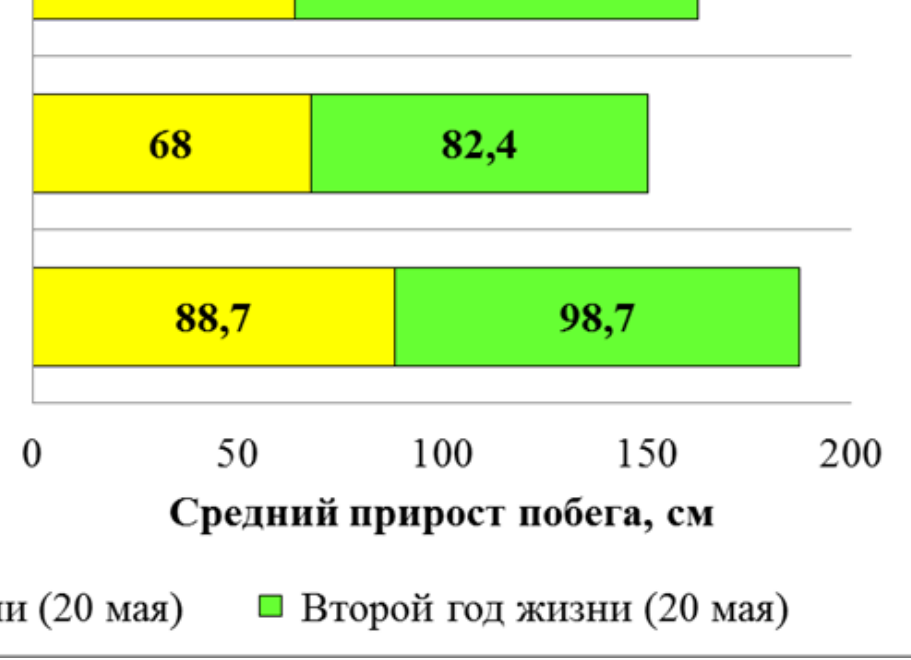

Первый год жизни (20 мая) $\square$ Второй год жизни (20 мая)

Рис. 4. Влияние субстрата на средний прирост побега в первые 2 календарных года жизни сеянцев винограда

Bblводb. Для сокращения длительности селекции на 3-4 года, целесообразно замачивание семян перед посевом до стратификации в растворе гибберелловой кислоты длительностью 24 часа, что обеспечивает выход сеянцев на уровне $91,2 \%$.

Подбор субстрата для выращивания гибридных сеянцев винограда также оказывает влияние на сроки селекционного процесса. На предлагаемом субстрате с составом - конский навоз + глауконитовый песок + Грин Го 8-16-4 + 10СаO + чернозем (1:1:1:1) - обеспечивается высокий выход сеянцев $-88,7 \%$, что выше, чем в прототипе на $24,7 \%$, приживаемость сеянцев на постоянном месте - 98,7\%. 


\section{Литература}

1. Зармаев А.А., Борисенко М.Н. Селекция, генетика винограда и ампелография. От теории к практике. Симферополь: ООО «Форма», 2018. 330 с.

2. Клоновая селекция - основа устойчивого развития виноградарства // Мобилизация и сохранение генетических ресурсов винограда, совершенствование методов селекционного процесса: сб. науч. статей / В.С. Петров [и др.]. Новочеркасск: ГНУ ВНИИВиВ им. Я.И. Потапенко, 2008. С. 128-133.

3. Агроэкологические основы виноградарства / А.М. Авидзба [и др.]. Симферополь: Таврия плюс, 2000. 67 с.

4. Потапенко А.И. Русский зимостойкий виноград. Смоленск: Унирерсум, 2007. $160 \mathrm{c}$.

5. Варасова Н.Н., Шустова А.П. Физиология растений. Л.: Колос, 1969. 222 с.

6. Игаунис Г.А. Биологические основы ускоренного выращивания сеянцев древесных пород. Рига: Зинатне, 1974. 133 с.

7. Гусев Н.А. Физиология водообмена растений. Казань: Изд-во Казанс. ун-та, 1966. $136 \mathrm{c}$.

8. Mauer 0. Morfologicke, anatomicke a fyziologicke,aspekty vyroby semenacku pod PE kryty. Lesn. cos., 1980, zv.26, n.2,s.115 - 127.

9. Muhle 0. Erte Erfahrungen mit Douglasien Containerpf-lanzen in nordwestdeutschland. - Forst - und Holzwirt, 1976, Bd.31,tT.15, s.305 - 307.

10. Nguyen V.T. A foliahaz liatasa az erdiefenyo esemete hajtasanak beeresere. Erdo, 1977, sz.8, old.349 - 352.

11. Parr L. A "Burkolt gyokeru csemetek alkalmmazasa az erdositesben. Erdesz. kut., 1975, k.71, n.1, old.61 - 77.

12. Стимуляция всхожести семян и развитие гибридных сеянцев / Г.П. Малых [и др.] // Виноделие и виноградарство. 2003. № 4. С. 43-45.

13. Овчаров К.Е. Физиологические основы всхожести семян. Москва: Наука, 1969. $103 \mathrm{c}$.

14. Мержаниан А.С. Виноградарство. Москва: Пищепромиздат, 1951. 524 с.

15. Негруль А.М. Виноградарство и виноделие. М.: Колос, 1968. 512 с.

16. Furuta T. Nitrogen fertilization of container-grown ornomentals. Am. Nurseryman, 1976, vol.143, p.12-14, 106 - 109.

17. Gartner J. Researches study pine and hardwood barks for use as container growing mediums. Am. Nurseryman, 1979, vol.149, a.1, p.13*

18. Kawase M. Wooster tube - this is a new way to put field grown plants in containers. - Seed Nersery Trader, 1980, vol.78, n. 2, стр. 7 - 11.

19. Cadot, Y. Anatomical, histological and histochemical changes in grape seeds from Vitis vinifera L.cv Cabernet franc during fruit development / Y. Cadot, M. T. Minana Castello, M. Chevalier // Journal of Agricultural and Food Chemistry. - 2006. - № 54. - P. 9206 - 9215.

20. Chellemi, D.O. Sporulation of Uncinula necator on Grape Leaves as Influenced by Temperature and Cultivar / D.O. Chellemi, J.J. Marois // Phytopathology. - 1991, Vol. 81. № 2. - P. $197-201$.

21. Frost, A.R. A pesticide injection metering system for use on agricultural spraying machines / A.R. Frost // J. Agric. Eng. Res. - 1990. - № 46. - P. 55 - 70.

\section{References}

1. Zarmaev A.A., Borisenko M.N. Selekciya, genetika vinograda i ampelografiya. Ot teorii k praktike. Simferopol': OOO «Forma», 2018. 330 s. 
2. Klonovaya selekciya - osnova ustojchivogo razvitiya vinogradarstva // Mobilizaciya i sohranenie geneticheskih resursov vinograda, sovershenstvovanie metodov selekcionnogo processa: sb. nauch. st. / V.S. Petrov [i dr.] // GNU Vseros. NII vinogradarstva i vinodeliya im. Ya.I. Potapenko Rossel'hozakademii. Novocherkassk: GNU VNIIViV im. Ya.I. Potapenko, 2008. S. 128-133.

3. Agroekologicheskie osnovy vinogradarstva / A.M. Avidzba [i dr.]. Simferopol': Tavriya plyus, 2000. $67 \mathrm{~s}$.

4. Potapenko A.I. Russkij zimostojkij vinograd. Smolensk: Unirersum, 2007. 160 s.

5. Varasova N.N., Shustova A.P. Fiziologiya rastenij. L.: Kolos, 1969. $222 \mathrm{s.}$

6. Igaunis G.A. Biologicheskie osnovy uskorennogo vyrashchivaniya seyancev drevesnyh porod. Riga: Zinatne, 1974. 133 s.

7. Gusev N.A. Fiziologiya vodoobmena rastenij. Kazan': Izd-vo Kazans. un-ta, 1966. $136 \mathrm{~s}$.

8. Mauer 0. Morfologicke, anatomicke a fyziologicke,aspekty vyroby semenacku pod PE kryty. Lesn. cos., 1980, zv.26, n.2,s.115 - 127.

9. Muhle 0. Erte Erfahrungen mit Douglasien Containerpf-lanzen in nordwestdeutschland. - Forst - und Holzwirt, 1976, Bd.31,tT.15, s.305 - 307.

10. Nguyen V.T. A foliahaz liatasa az erdiefenyo esemete hajtasanak "eeresere. Erdo, 1977, sz.8, old.349 - 352.

11. Parr L. A \"Burkolt gyokeru csemetek alkalmmazasa az er-dositesben. Erdesz. kut., 1975, k.71, n.1, old.61 - 77.

12. Stimulyaciya vskhozhesti semyan i razvitie gibridnyh seyancev / G.P. Malyh [i dr.] // Vinodelie i vinogradarstvo. 2003. № 4. S. 43-45. 1969. $103 \mathrm{~s}$.

13. Ovcharov K.E. Fiziologicheskie osnovy vskhozhesti semyan. Moskva: Nauka,

14. Merzhanian A.S. Vinogradarstvo. Moskva: Pishchepromizdat, 1951. $524 \mathrm{~s}$.

15. Negrul' A.M. Vinogradarstvo i vinodelie. M.: Kolos, 1968. $512 \mathrm{~s}$.

16. Furuta T. Nitrogen fertilization of container-grown ornomentals. Am. Nurseryman, 1976, vol.143, p.12-14, $106-109$.

17. Gartner J. Researches study pine and hardwood barks for use as container growing mediums. Am. Nurseryman, 1979, vol.149, a.1, p.13*

18. Kawase M. Wooster tube - this is a new way to put field grown plants in containers. - Seed Nersery Trader, 1980, vol.78, n. 2, str. 7 - 11.

19. Cadot, Y. Anatomical, histological and histochemical changes in grape seeds from Vitis vinifera L.cv Cabernet franc during fruit development / Y. Cadot, M. T. Minana Castello, M. Chevalier // Journal of Agricultural and Food Chemistry. - 2006. - № 54. - R. 9206 - 9215.

20. Chellemi, D.O. Sporulation of Uncinula necator on Grape Leaves as Influenced by Temperature and Cultivar / D.O. Chellemi, J.J. Marois // Phytopathology. - 1991, Vol. 81. № 2. - P. $197-201$.

21. Frost, A.R. A pesticide injection metering system for use on agricultural spraying machines / A.R. Frost // J. Agric. Eng. Res. - 1990. - № 46. - P. 55 - 70. 